\title{
O PROJETO POLÍTICO-PEDAGÓGICO E CURRÍCULO DA EFAU: EDUCAÇÃO PARA QUE? E PARA QUEM? ${ }^{1}$
}

\author{
Ana Paula do AMARAL ${ }^{2}$ \\ Ilma Ferreira MACHADO ${ }^{3}$
}

RESUMO: Este trabalho tem por objetivo analisar os pressupostos ontológicos, a ideologia e a efetivação diária do Projeto político-pedagógico da Escola Família Agrícola de Uirapuru-GO (EFAU) e sua relação com o currículo diferenciado proposto pela Pedagogia da Alternância, em que os tempos e espaços educativos não se dão exclusivamente na escola, mas também nas comunidades rurais. Sendo assim, buscou-se socializar dados de um projeto de pesquisa que procurou analisar a configuração da Pedagogia da Alternância na EFAU, seus limites e potencialidades, baseando-se em uma metodologia de pesquisa qualitativa, numa perspectiva participante. Nesse processo investigativo, entrevistou-se educadores, estudantes, funcionários/monitores e pais, observando de forma participativa o cotidiano da escola, além de analisar documentos históricos, como o Projeto político-pedagógico (PPP) e Regimento Escolar. Em específico, as correlações entre o PPP e currículo buscam sistematizar e socializar as falas dos educadores e suas reflexões sobre a Pedagogia da Alternância no cotidiano da escola, no sentido de contribuir para ações e debates no âmbito da Educação do Campo.

PAlaVRAS-CHAVE: Projeto político-pedagógico. Currículo. Pedagogia da Alternância.

\section{INTRODUÇÃO}

O presente artigo objetiva analisar os pressupostos ontológicos contidos no Projeto político-pedagógico da Escola Família Agrícola de Uirapuru-GO (EFAU) e sua relação com a construção de um currículo escolar diferenciado sustentado pela Pedagogia da Alternância e seus pilares fundamentais. As análises desse trabalho proveem de uma investigação qualitativa e de caráter participante realizada no ano de 2012, onde foram entrevistados os pais, estudantes, educadores e funcionários/monitores da EFAU, além de examinar documentos históricos e observar, de forma participativa, esses sujeitos em seus cotidianos.

Desse modo, a Pedagogia da Alternância desenvolvida na EFAU, bem como em outras Escolas Famílias Agrícolas (EFAs) do Brasil, procura alternar tempos e espaços

\footnotetext{
${ }^{1}$ A análise desse artigo é parte da dissertação de Mestrado em Educação intitulada "A configuração da pedagogia da alternância na Escola Família Agrícola de Uirapuru-GO: limites e potencialidades"

${ }^{2}$ Mestre em Educação. UNEMAT - Universidade do Estado de Mato Grosso. Carceres - MT - Brasil. 78200-000. Escola Família Agrícola de Uirapuru. Uirapuru - GO - Brasil - ana_ufla@ yahoo.com.br

${ }^{3}$ Doutora em Educação. UNICAMP - Universidade Estadual de Campinas. Campinas - SP - Brasil. 13083-970. UNEMAT - Universidade do Estado de Mato Grosso. Cáceres - MT - Brasil. 78200-000 ilma.ferreiramachado@gmail.com
} 
de aprendizado, onde os estudantes permanecem quinze (15) dias em sistema de internato na escola e quinze (15) dias na comunidade, buscando relacionar escola e família no meio rural.

No que diz respeito às EFAs no Brasil, estas possuem uma caminhada histórica de mais de quarenta anos de existência e estão espalhadas por quase todo o território do país, se constituindo através de quatro pilares fundamentais que são: a alternância de tempos e espaços de aprendizado; a formação integral dos estudantes; o desenvolvimento do meio e a associação comunitária como forma de manutenção e sustentação político-financeira dessas escolas. Portanto, as EFAs possuem em seus pressupostos a articulação entre a escola, família e comunidade rural, alternando tempos e espaços educativos na tentativa de relacionar o trabalho à educação de jovens, tanto do Ensino Fundamental quanto de nível Médio.

Numa abordagem histórica, Ribeiro (2010), ao buscar as origens da Pedagogia da Alternância, evidencia que ela surge como uma alternativa de formação para os filhos de agricultores na França no século XX. Sendo que a primeira experiência sistematizada nessa perspectiva possui referência nas práticas das Maison Familiale Rurale (MFRs) francesas e nos sindicatos de trabalhadores rurais. Estas organizações foram pioneiras no sentido de organizar os interesses dos agricultores insatisfeitos com o ensino formal dado aos seus filhos e de dar concretude aos interesses comuns, tanto na própria França quanto em vários outros países em diversos continentes do planeta ${ }^{4}$.

A alternância, praticada pelas MFRs, foi sempre considerada, desde sua criação, uma forma diferenciada de formação para os jovens camponeses sem, no entanto, terem que sair do campo. Assim, dessa necessidade, surge no ano de 1935, em Lauzun, na região sudoeste da França, a primeira Casa Familiar Rural francesa, organizada através da iniciativa de três agricultores locais e um pároco (GIMONET, 1999). Seu nascimento tem, portanto, localização extraescolar, sendo fruto de um descontentamento por parte dos pais em relação ao ensino formal dado aos seus filhos, indicando assim os primeiros passos de uma educação popular.

Para Ribeiro (2010, p.293), não só havia descontentamento por parte dos pais, mas também por parte dos jovens franceses dessa região, que estavam desanimados com

\footnotetext{
${ }^{4}$ Marlene Ribeiro (2010) referenciada nos estudos de Duffaure (1997) sobre um levantamento de Casas Familiares Rurais no mundo registrou experiências na França, Itália, Portugal, Filipinas, Algéria, Senegal, Benin, Camarões, Etiópia, Gabão, Congo, África Central, Ruanda, Chade, Tongo, Tunísia, Zaire, Costa do Marfim, Madagascar, Ilhas Maurício, Argentina, Chile, El Salvador, Guatemala, Honduras, México, Nicarágua, Panamá, República Dominicana, Uruguai e Venezuela.
} 
o ensino escolar proposto, pois não "[...] estabelecia nenhuma forma de articulação com o modo de vida e trabalho dos camponeses."

Assim, desde sua origem, a Pedagogia da Alternância se propõe a articular a realidade com a necessidade do ensino escolarizado, já que a escola oferecida a esses jovens propunha a construção de um curso de caráter técnico, focado na agricultura e na realidade da região. Os estudantes passavam uma semana na casa paroquial, lugar cedido como escola, onde discutiam e estudavam os trabalhos realizados na propriedade junto às suas famílias (FANCK, 2007).

Para Gimonet (2007, p.22), o nascimento da primeira MFR se deu de modo muito simples.

\begin{abstract}
Simplicidade de um problema posto em 1935, num vilarejo na França, para uns pais agricultores: seu filho, um adolescente, não querer ir para a escola secundária; simplicidade da questão decorrente disto: "o que propor-lhe para continuar os estudos?"; simplicidade do encontro com o vigário do povoado, na beira na estrada, para expor esse problema; simplicidade da solução encontrada com os outros: "criar uma escola que não mantenha os adolescentes presos entre quatro paredes, mas que lhes permitam aprender através dos ensinamentos da escola, com certeza, mas também através daqueles da vida quotidiana, graças a uma alternância de períodos entre o ambiente familiar e o centro escolar."
\end{abstract}

$\mathrm{Na}$ atualidade, essa questão da simplicidade abordada por Gimonet (2007), tornou-se uma complexa articulação entre os tempos/espaços de aprendizado, com uma série de aparatos metodológicos e orientações pedagógicas, na tentativa de articular a prática e a teoria nos diversos contextos sociais na qual se insere.

É nesse sentido que, para Ribeiro (2010, p.292), “[...] a pedagogia da alternância, em tese, articula prática e teoria em uma práxis.”, pois carrega em si, incluindo todas as limitações que impedem essa articulação, uma atividade destinada a um fim, de caráter real e objetivo, ou como afirma Vásquez (2011 p.277) “transforma o mundo exterior" através da consciência de si e da natureza. Ela visa em alguma instância transformar a realidade.

Nesse caso, a alternância se movimenta no sentido da ação, partindo da prática e indo ao encontro da teoria, pois propõe, em diferentes escalas, não descartar a importância da prática dos estudantes em suas comunidades e nem mesmo o aprendizado e a experiência adquiridos. Assim, se configura como práxis educativa na medida em que alia o pensar e o agir numa perspectiva transformadora. 
Tendo claro essas questões, esse artigo socializa essa experiência educativa diferenciada da EFAU, focando o Projeto político-pedagógico dessa escola, relacionando-o com a construção de um currículo, que se norteia, com todas as dificuldades, pela perspectiva da atuação crítica e transformadora dos sujeitos que estão na escola e fora dela.

\section{O PROJETO POLÍTICO-PEDAGÓGICO (PPP) DA ESCOLA FAMÍlIA AGRÍCOLA DE UIRAPURU: EDUCAÇÃO PARA QUE? E PARA QUEM?}

Em nossa compreensão, um projeto pedagógico de uma escola não se dissocia das questões políticas, portanto é intencional e comprometido com realidade sociopolítica concreta (VEIGA, 1995). Dessa forma, entender o desenho de um PPP, seus pressupostos ontológicos, sua ideologia e sua efetivação diária, passa pela própria organização do trabalho pedagógico, que nesse caso específico, é referenciado na Pedagogia da Alternância. Nessa perspectiva, o PPP deve possuir um rumo, uma direção no sentido de quais ações educativas e pedagógicas pretende-se desenvolver, qual formação almeja-se e para que tipo de sociedade. Isso está intimamente relacionado com princípios orientadores do Projeto, que são, segundo Veiga (1995), igualdade, qualidade, gestão democrática, liberdade e valorização dos educadores.

Em nosso campo empírico particular, a EFAU, procuramos observar nos documentos internos da escola que dizem respeito à sua proposta educativa e pedagógica, as finalidades e os objetivos almejados por essa escola, sua estrutura organizacional, o currículo e a organização do tempo/espaço educativo, entendendo que a "[...] proposta pedagógica ajuda a clarear os rumos e ações da escola, e nortear a prática educativa dos professores.” (MACHADO, 2003, p.314).

No que tange à finalidade política e social da EFA de Uirapuru, podemos identificá-la nos "Objetivos Geral e Específicos do PPP”, onde a formação do estudante está associada ao exercício da cidadania e à aquisição de habilidades e competências, relacionadas às habilidades agronômicas e zootécnicas, tanto na ordem da assistência técnica e extensão rural, quanto na inserção profissional em processos organizativos de cooperativas/associações. Além disso, a formação humana é também abordada, focando o desenvolvimento da pessoa associada à ética, criticidade, construção de identidades na convivência grupal e ao desenvolvimento da autonomia intelectual.

Já no item “Justificativa do PPP”, observamos que há um evidente recorte social e político quando se analisa a realidade local, explicitando suas contradições sociais, 
como, por exemplo, na descrição da região de Uirapuru, da agricultura familiar desenvolvida no município e da problemática no campo, principalmente relacionada aos jovens camponeses e ao processo de migração para as cidades e suas consequências. Uma abordagem que entende esse território ${ }^{5}$ como espaço próprio de cultura, economia e política, mas que, não obstante, se insere em um todo maior de uma sociedade onde impera a luta de classes.

Dessa maneira, a região, apesar de ser marcada fortemente pela presença do campesinato, onde a pecuária leiteira se coloca como espaço de recriação das identidades, também apresenta as imposições do sistema global de produção, configurado no agronegócio/latifúndio, sustentado pela pecuária extensiva, pelos frigoríficos e pelas cooperativas de leite. Este é o contexto que desencadeia a própria constituição da EFAU e passa a orientar os seus objetivos, explicitados no PPP.

Observamos que a formação humana também é uma busca constante dessa escola, mas no PPP ela aparece de forma pouco aprofundada. Será no Regimento Escolar que ela aparecerá assentada nos princípios da Pedagogia da Alternância como formação necessária ao desenvolvimento do jovem, na qualificação para o trabalho e no exercício da cidadania fundada em valores de liberdade, igualdade, fraternidade, dignidade e respeito. Isso de certo modo, expressa a formação da personalidade requerida na base teórica da alternância dos CEFFAs (Centros Familiares de Formação em Alternância $)^{6}$, referenciados no personalismo e valorização da pessoa humana do filósofo Mounier.

Sobre o perfil profissional e o desenvolvimento das chamadas competências e habilidades dos estudantes matriculados na EFAU, é possível notar que todas as habilidades são muito bem descritas pelo PPP, que visa entre outras coisas, contribuir com o desenvolvimento sustentável e o fortalecimento dos saberes e da cultura regional. Mas, o grande entrave é que a ementa de algumas disciplinas, tanto da base técnica quanto da base comum do Ensino Médio Integrado, ainda se restringe às atribuições exigidas pelo MEC e pelo CREA (Conselho Regional de Engenharia, Arquitetura e

\footnotetext{
${ }^{5}$ Território, nesse trabalho, refere-se à diversidade no campo e também às disputas sócio-políticas no campo e suas consequências para o trabalhador. De um lado o território do agronegócio/latifúndio, operacionalizado pelas multinacionais oligopolistas e por outro, o campesinato como diversidade de modos de ser e viver em sociedade, que por possuírem um projeto de desenvolvimento distinto, se opõem (GIRARDI, 2008).

${ }^{6}$ CEFFAs: organização que congrega as mais de 200 escolas que tem como base de funcionamento a Pedagogia da Alternância no Brasil.
} 
Agronomia), o que limita, muitas vezes, articular esse conteúdo exigido com os aspectos da realidade local, tão bem descritos no PPP e Regimento escolar.

O entendimento de que a alternância de tempos/espaços de aprendizado só se concretiza com a clareza do que ela é e representa, foi evidenciado pela maioria dos educadores da escola, nas entrevistas, que, em contrapartida, revelaram que alguns desses profissionais desconhecem essa proposta educativa, o que impõe a necessidade de interação entre os educadores da escola e formação continuada sobre o tema. Ou seja, essa contradição influencia diretamente na prática desses educadores que, muitas vezes, não se sentem instrumentalizados para realizar a tarefa complexa de articular os conhecimentos científicos aos conhecimentos populares, ou seja, aqueles comumente socializados nas comunidades dos estudantes.

Sobre essas incoerências, podemos compreendê-las melhor quando, ao fazer um trabalho de estudo e reflexão em conjunto com educadores e funcionários/monitores no ano de 2011 sobre o PPP, verificamos que desde a sua elaboração até aquele presente momento, não houve nenhuma retomada ou avaliação desse documento. Como afirma Veiga (1995, p.32) “[...] acompanhar as atividades e avaliá-las levam-nos à reflexão, com base em dados concretos sobre como a escola organiza-se para colocar em ação seu projeto político-pedagógico."

Com relação à estrutura organizacional da escola, verificamos no PPP uma descrição detalhada de sua estrutura física, ou melhor, dos materiais didáticos, dos prédios, das instalações da área produtiva, dos equipamentos, do tamanho da propriedade, entre outros. Mas, diferentemente da realidade, essa descrição parece não coincidir com o que observamos. O que parece haver, de fato, é certo receio em declarar a falta de estrutura e as dificuldades financeiras enfrentadas pela escola e, por esse motivo, algumas questões são omitidas.

No que diz respeito à estrutura pedagógica, ou como destaca Veiga (1995), àquelas questões referentes às interações políticas, ao processo ensino- aprendizagem e ao currículo, podemos verificar, no PPP, que refletem de modo geral alguns princípios da Pedagogia da Alternância, principalmente enquanto um regime que alterna situações de aprendizagem na escola e na família, mas de modo muito tímido e restrito às questões de carga horária.

Já o currículo da EFAU se propõe a incorporar, junto às exigências das normas em vigor, as necessidades dos agricultores familiares da região, visando à formação integral dos estudantes, possibilitando-lhes uma visão de mundo, entendida aqui como 
uma visão da totalidade. Os programas disciplinares e o planejamento didático são propostos a partir do PPP, para serem construídos, pelo menos em tese, junto à coordenação pedagógica da escola, evidenciando um processo coletivo e democrático na estrutura pedagógica.

Assim, a organização curricular do Ensino Médio integrado ao Curso Técnico em Agropecuária se divide em três Bases. A Base Comum do Ensino Médio que contempla as disciplinas de Português, Inglês, Educação Física, Química, Biologia, Matemática, Geografia, História, Filosofia e Sociologia; a Base Comum da Educação Profissional contemplando Topografia, Agricultura, Fruticultura, Projetos Agropecuários, Olericultura e Jardinagem, Culturas Anuais, Culturas Perenes, Agroindústria, Construções e Instalações Rurais, Irrigação e Drenagem, Gestão Ambiental e Silvicultura, Mecanização Agrícola, Zootecnia Geral, Animais de pequeno porte, Animais de médio porte, Animais de grande porte, Estágio Supervisionado e a Base Articuladora com as disciplinas de Formação humana e religiosa, Introdução a projetos, Organização para a gestão, Informática aplicada e Contabilidade aplicada.

Pela análise do currículo da EFAU, observamos que ele é diferenciado, principalmente porque não se dá exclusivamente em um tempo escolar, mas também no tempo em que os estudantes permanecem na família, como podemos verificar no exemplo da disciplina de Língua Portuguesa, onde são exigidas 215 aulas anuais, semanalmente cinco (05) aulas são da Sessão Escolar ou Tempo Escola e cinco (05) da Sessão Familiar ou Tempo Comunidade. As cinco (05) aulas que devem ser trabalhadas na família, são contabilizadas através de trabalhos encaminhados na Sessão Escolar e também pelos instrumentos pedagógicos.

Uma questão importante é a percepção de que a Pedagogia da Alternância se revela diferente em sua proposta educativa, principalmente pela utilização dos instrumentos pedagógicos que, segundo Begnami (2010), surgiram da prática e das reflexões de pedagogos orgânicos ao movimento dos CEFFAs. Os instrumentos são o Plano de Estudo, Caderno de Acompanhamento, Caderno da Realidade, Tutoria, Visita às famílias/comunidade, Projeto Profissional do Jovem (PPJ), Colaborações externas, Estágios, Serões, Viagens de estudo, Colocação em Comum, Caderno Didático, Avaliações e Atividades de Retorno. 
No caso da EFAU, os instrumentos que fazem parte do seu cotidiano são o Caderno da Realidade; Caderno de Acompanhamento; as 'notinhas,7; o Serão; visitas às famílias; Plano de Estudo, Acompanhamento Personalizado (Tutoria) e Projeto Profissional do Jovem (PPJ). Como pudemos observar apenas alguns funcionam, mas sabemos por relatos informais de alguns funcionários/monitores, que nem sempre foi assim, pois já houve momentos em que os instrumentos foram trabalhados e a escola obteve o retorno esperado. O que se tem hoje é uma tentativa de colocá-los em prática, mas com muita dificuldade.

Podemos apontar que esses instrumentos refletem aquilo que Ribeiro (2009) de pragmatismo e instrumentalização da "educação para ação", aclamados pela Escola Nova. Esses instrumentos são evidenciados pela autora nas referências dos CEFFAs ao Construtivismo do biólogo suíço Jean Piaget e sua crítica severa à maneira como se processa o ensino e a aprendizagem no tradicionalismo escolar.

Assim, os instrumentos pedagógicos utilizados pelas EFAs se caracterizam por atividades que coordenam as ações na Sessão escolar e na Sessão familiar desenvolvidos, em tese, por estudantes, educadores, monitores e funcionários, que contribuem para o funcionamento coletivo da escola tendo como horizonte a conscientização e mudança de postura frente à necessidade do trabalho em grupo. $\mathrm{O}$ que, segundo a maioria dos sujeitos da pesquisa declarou, através das entrevistas, foi considerada muito importante, já que observam mudanças na vida dos estudantes e suas famílias.

Para Gimonet (2007), os instrumentos, as atividades, as técnicas significam uma "partilha do poder educativo", sendo resultantes dos princípios e finalidades da própria pedagogia da alternância. Para o autor, são

[...] atividades e instrumentos de investigação dos espaços-tempos e experiências familiares, profissionais e sociais; atividades e instrumentos de junção entre o meio de vida e o CEFFA; atividades e instrumentos que dão acesso aos dados e disciplinas dos programas acadêmicos e de unificação dos saberes; atividades e instrumentos de avaliação; uma organização temática das sequencias da alternância como unidades de formação; uma orquestração do conjunto do percurso dado pelo Plano de Formação; uma organização específica das semanas de formação no CEFFA (planejamento semanal);

\footnotetext{
${ }^{7}$ As notinhas valem quatro (04) pontos do total de pontos por disciplina que são dez (10). Correspondem a: pontualidade ( 1 ponto), habilidade ( 1 ponto), convivência ( 1 ponto) e Cadernos da realidade e de acompanhamento (1 ponto).
} 
atividades e instrumentos de relacionamento entre os co-formadores. (GIMONET, 2007, p.31).

Com relação ao posicionamento dos educadores frente ao conhecimento e ao papel dos instrumentos pedagógicos, podemos inferir que nem todos conhecem e acompanham seu desenvolvimento, já que para que muitos desses instrumentos se concretizem, educadores e funcionários/monitores, necessariamente, precisam estar presentes nas comunidades dos estudantes. E ainda, podemos notar que alguns educadores desconhecem completamente os instrumentos, como afirmaram nas entrevistas, evidenciando certo distanciamento desses sujeitos com relação à alternância.

Nesse sentido, se esses instrumentos compõem a ação pedagógica da escola, como salienta Gimonet (2004), verificamos pelas falas, que há uma lacuna que necessita ser preenchida na EFAU, principalmente por quem coordena a escola e está mais a frente desse processo, ou seja, os mais preparados e que possuem uma caminhada mais longa com relação a essa proposta. A impossibilidade de trabalharem apenas na EFAU e a falta de auto-organização desses profissionais limitam ações mais efetivas na escola e que alterem o quadro de não concretização da articulação entre os tempos/espaços de aprendizado.

Outra questão importante do currículo é que ele se propõe integrador e se constrói dentro de um Plano de Formação que, através do instrumento pedagógico chamado "Plano de Estudo", deve articular as disciplinas e todas as atividades escolares através de um Tema Gerador, escolhido de forma intencional e orientado pela realidade e contexto social. Assim, segundo os documentos aos quais tivemos acesso na escola, os Planos de Estudos são trabalhados por série/ano, sendo um tema por bimestre. Estes temas são aprovados, em tese, em assembleia das famílias, estudantes e equipe pedagógica, por isso, estão sujeitos a mudanças anualmente.

No caso do primeiro ano do Curso Técnico o Plano de Estudo ou o Tema Gerador do primeiro bimestre de 2011 foi "A importância da minha família perante os desafios da sociedade atual", que fica sob a responsabilidade de um funcionário/monitor ou educador, devendo ser explorado tanto nas disciplinas quanto nas atividades comuns do Tempo Escola ou Sessão Familiar, como, por exemplo, nas atividades culturais conhecidas como Serão. Mas o que observamos é que esses temas são poucos 
explorados em sala de aula, pois falta articulação e planejamento entre os educadores e coordenação da escola para concretizar esse instrumento pedagógico.

Desse modo, se as análises das estruturas, tanto administrativas quanto pedagógicas, visam, segundo Veiga (1995), identificar as relações existentes entre elas e compreender suas características e seus embates, a Escola Família Agrícola de Uirapuru possui certa limitação em explicitar essas questões em seu Projeto político-pedagógico, o que pode vir a refletir, entre outras coisas, nas dificuldades de se tomar decisões reais e passíveis de execução (VEIGA, 1995). Esta reflexão leva-nos a uma discussão fundamental: o PPP é uma burocracia ou manifestação real dos propósitos da escola?

Sob essa perspectiva, concordamos com Veiga (1995, p.26) quando afirma que,

[...] ao situar os obstáculos e vislumbrar as possibilidades, os educadores vão desvelando a realidade escolar, estabelecendo relações, definindo finalidades comuns e configurando novas formas de organizar as estruturas administrativas e pedagógicas para a melhoria do trabalho de toda a escola na direção do que se pretende.

Para concluir, cabe dizer que o PPP, entendido como instrumento que caracteriza a própria organização do trabalho pedagógico, deve refletir, como afirma Machado (2008), certos fundamentos referenciados na interpretação e compreensão do mundo, no conhecimento como produção humana e coletiva, no trabalho como principio educativo, na autonomia e na auto-organização, tanto discente quanto docente. Dessa maneira, o Projeto político-pedagógico terá claro em seus pressupostos as concepções de sociedade, de conhecimento, de ser humano e de educação que deseja construir (MACHADO, 2008).

\section{THE POLITICAL-PEDAGOGICAL PROJECT AND CURRICULUM EFAU: EDUCATION FOR WHAT? AND FOR WHOM?}

ABSTRACT: This work has objective to analyze the ontological pre-suppositions, the ideology and the daily effectuation of the political pedagogical Project in the Agricultural Family School of Uirapuru-GO, and its relationship with the differentiated curriculum proposed by Pedagogy of Alternation, in which the times and the educational spaces do not happen exclusively in school, but also in rural community. Thus, we sought to socialize data of a research project that searched aimed to analyze the configuration of Pedagogy of Alternation at EFAU, its limits and potentials, based on a qualitative research methodology, in a participating perspective. In this investigative process, educators, students, employees and parents have been interviewed, observing in a participative way the school's every day, besides analyzing historical documents, such as the political pedagogy Project and School Regiment. In 
specific, the correlations between the PPP and curriculum try to systematize and to socialize the speech of educators and their reflections about the Alternation of Pedagogy in daily school, meaning to contribute to actions and debates concerning Field Education.

KEYWORDS: Political-Pedagogical Project. Curriculum. Pedagogy of Alternation.

\section{REFERÊNCIAS}

BEGNAMI, M. J. F. Inserção profissional de jovens do campo: desafios e possibilidades dos jovens egressos da Escola Família Agrícola de Bontempo. 2010. 184f. Dissertação (Mestrado em Educação) - Universidade Federal de Minas Gerais, Belo Horizonte, 2010.

FANCK, C. Entre a enxada e o lápis: a prática educativa da Casa Familiar Rural de Francisco Beltrão/ PR. 2007. 149f. Dissertação (Mestrado em Educação) Universidade Federal Rural de Rio de Janeiro, Porto Alegre, 2007.

GIMONET, J. C. Praticar e compreender a Pedagogia da Alternância do CEFFAs. Petrópolis: Vozes, 2007.

Método pedagógico ou novo sistema educativo? a experiência das Casas Familiares Rurais. Brasília: UNEFAB, 2004. (Documentos Pedagógicos da UNEFAB).

Nascimento e desenvolvimento de um movimento educativo: as Casas Familiares Rurais de Educação e de reorientação. In: SEMINÁRIO INTERNACIONAL DA PEDAGOGIA DA ALTERNÂNCIA, 1., 1999, Salvador. Anais... Salvador: União Nacional das Escolas Famílias Agrícolas do Brasil, 1999. p.39-48.

GIRARDI, E. P. Proposição teórico-metodológico de uma cartografia crítica e sua aplicação no desenvolvimento do atlas da questão agrária brasileira. 2008. 347f. Tese (Doutorado em Geografia) - Faculdade de Ciências e Tecnologia, Universidade Estadual Paulista, Presidente Prudente, 2008.

MACHADO, I. F. Qual a organização curricular necessária à escola do campo? In: CARVALHO, D.; GRANDO, B.; BITTAR, M. Currículo, diversidade e formação. Florianópolis: Ed. da UFSC, 2008. p.191-206.

. A organização do trabalho pedagógico em uma escola do MST e a

perspectiva de formação omnilateral. 2003. 325f. Tese (Doutorado em Educação) Universidade Estadual de Campinas, Campinas, 2003.

RIBEIRO, M. Movimento camponês, trabalho e educação: liberdade, autonomia, emancipação: princípios / fins da formação humana. São Paulo: Expressão Popular, 2010.

. Trabalho e educação no movimento camponês: liberdade ou emancipação?

Revista Brasileira de Educação, Rio de Janeiro, v.14, n.42, p.423- 601, set./dez. 2009.

VASQUEZ, A. S. Filosofia da práxis. 2.ed. São Paulo: Expressão Popular, 2011.

VEIGA, I. P. Projeto político- pedagógico da escola: uma construção coletiva. In:

VEIGA, I. P. (Org.). Projeto político-pedagógico da escola: uma construção possível. Campinas: Papirus, 1995. p.09- 35. 